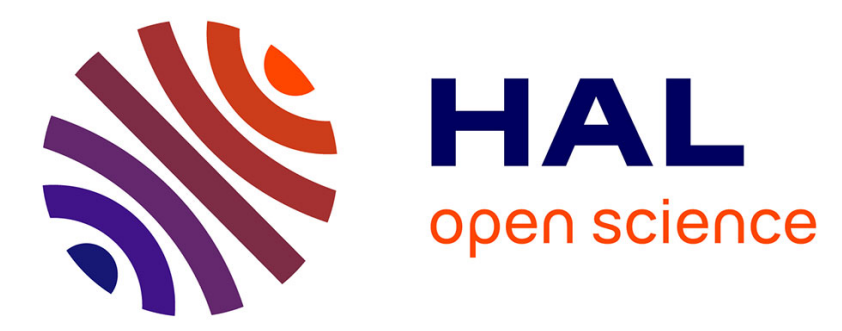

\title{
Development of an analytical methodology for obtaining quantitative mass concentrations from LAAP-ToF-MS measurements
}

\author{
R Gemayel, B Temime-Roussel, N Hayeck, A Gandolfo, S Hellebust, S \\ Gligorovski, Henri Wortham
}

\section{To cite this version:}

R Gemayel, B Temime-Roussel, N Hayeck, A Gandolfo, S Hellebust, et al.. Development of an analytical methodology for obtaining quantitative mass concentrations from LAAP-ToF-MS measurements. Talanta, 2017, 174, pp.715-724. 10.1016/j.talanta.2017.06.050 . hal-01635700

\author{
HAL Id: hal-01635700 \\ https://hal.science/hal-01635700
}

Submitted on 25 Apr 2018

HAL is a multi-disciplinary open access archive for the deposit and dissemination of scientific research documents, whether they are published or not. The documents may come from teaching and research institutions in France or abroad, or from public or private research centers.
L'archive ouverte pluridisciplinaire HAL, est destinée au dépôt et à la diffusion de documents scientifiques de niveau recherche, publiés ou non, émanant des établissements d'enseignement et de recherche français ou étrangers, des laboratoires publics ou privés. 

Hellebust ${ }^{1 \#}$, Sasho Gligorovski*1,2 , Henri Wortham ${ }^{1} .{ }^{1}$ Aix Marseille Univ, CNRS, LCE, Marseille, France.

${ }^{2}$ State Key Laboratory of Organic Geochemistry, Guangzhou Institute of Geochemistry, Chinese Academy of Sciences, Guangzhou 510 640, China

Submitted to

Talanta

Correspondence to:

*e-mail: rachel.gemayel@etu.univ-amu.fr *e-mail: gligorovski@gig.ac.cn

ÿ Now at: Univ Lyon, Université Claude Bernard Lyon 1, CNRS, IRCELYON, F-69626, Villeurbanne, 


\section{Abstract}

2 Laser ablation aerosol particle-time of flight mass spectrometer (LAAP-ToF-MS) measures the

3 size number of particles, and chemical composition of individual particles in real-time. LAAP-

4 ToF-MS measurements of chemical composition are difficult to quantify, mostly because the instrument sensitivities to various chemical species in the multicomponent atmospheric aerosol particles are unknown. In this study, we investigate a field-based approach for quantitative measurements of ammonium, nitrate, sulfate, OC, and EC, in size-segregated atmospheric aerosols, by LAAP-ToF-MS using concurrent measurements from high-resolution time-offlight aerosol mass spectrometer (HR-ToF-AMS), and multi-angle absorption photometer (MAAP). An optical particle counter (OPC) and a high-resolution nanoparticle sizer (scanning mobility particle sizer, or SMPS), were used to measure the particle size distributions of the particles in order to correct the number concentrations. The intercomparison reveals that the degree of agreement of the mass concentrations of each compound measured with LAAP-ToFMS and HR-ToF-AMS/MAAP increases in the following order $\mathrm{NH}_{4}{ }^{+}<\mathrm{SO}_{4}{ }^{2-}<\mathrm{NO}_{3}{ }^{-}<\mathrm{EC}<\mathrm{OC}$ $<\mathrm{Cl}^{-}$with $\mathrm{r}^{2}$ values in the range of 0.4-0.95 and linear regression slopes ranging between 0.62 and 1.2. The factors that affect the mass concentrations measured by LAAP-ToF-MS are also discussed in details. Yet, the matrix effect remains one of the strongest limiting factor to achieve an absolute quantification of the aerosol chemical composition.

In the future we suggest the development of a methodology based on the calculation of the response factors generated by different types of particles, which could possibly resolve certain difficulties associated with the matrix effect.

Keywords: single aerosol; laser ablation, LAAP-ToF-MS; matrix effect; quantification. 
Introduction

Atmospheric aerosol particles largely influence the air quality in urban and semi urban environments. It is known that high particle mass concentrations can induce hazardous respiratory health effects [1]. Adverse health effects are associated with particles having aerodynamic diameters smaller than $2.5 \mu \mathrm{m}$ (PM 2.5). Namely, the size range of particles inferior of $2.5 \mu \mathrm{m}$ is well correlated with the human mortality rates [2]. A recently performed global atmospheric chemistry model [3] aimed to calculate the concentrations of pollutants, reported that 3.3 million people die prematurely every year as a result of air pollution, mostly associated with PM 2.5. These authors [3] predicted that by 2050 the number of particlesinduced deaths worldwide could rise to 6.6 million per year.

Also, aerosol particles have a large impact on Earth's climate by scattering and absorbing radiation and by serving as nuclei for cloud formation [4].

Comprehensive knowledge about the physical and chemical properties of aerosols is crucial for properly evaluating the effects of aerosols on human health, air quality and climate changes [5]. Therefore, long-term monitoring of atmospheric particles and quantification of chemically resolved composition in ambient particles is of paramount importance for developing legislative tools and creating clean air action plans. Recently, Gemayel et al. (2016) [6] presented the ability of a recently launched commercial single particle mass spectrometer, the laser ablation aerosol particle-time of flight mass spectrometer (LAAP-ToF-MS; Aeromegt GmbH) to detect and analyze atmospheric particles. However, the quantification of the chemical composition by laser desorption ionization (LDI) technique appears to be a challenging task due to inhomogeneous laser beam proýle [7] (the effects of the shot-to-shot single particle ion signal puctuations), size-dependent particle transmission efficiency and matrix effect on detection and ionization [8]. There is an important number of studies [9][10][11][12][13][14] which demonstrates that quantification of the chemical composition by LDI techniques is feasible by 
mathematical and comparative methods. The comparative approach consist to converts the ion intensity produced by LDI into mass concentration. The conversion is based on comparison to another techniques for particle analysis [15][10][8] [16] [17][18][19].

It has been questioned as to whether laser desorption ionization (LDI) analysis of aerosols can be used to quantitatively assess the amounts of specific chemical species such as organic compounds (OC) and elemental carbon (EC) in ambient particles. . Healy et al. (2013) and Jeong et al. (2011) developed the idea of quantifying aerosol chemical composition based on the specific ion intensities response factors using concurrent quantitative measurements including an Organic/Elemental carbon analyser and a high resolution time-of-flight aerosol mass spectrometer (HR-ToF-AMS) [18,19].

For example, aerosol time of flight mass spectrometer (ATOFMS) has been used in a number of atmospheric measurement campaigns and provides complementary information on aerosol chemistry and particle variability in the environment [20,21]. Single particle mass spectrometers such as ATOFMS provide information on the number concentrations of chemically distinct particle types, showing how these concentrations change over time [22,23]. The same methodology $[10,15,24]$ was also adopted in this study with an additional step based on the calculation of a response factor of the LAAP-ToF-MS for different size ranges in order to quantify several chemical compounds.

In this study we compared the performances of LAAP-ToF-MS against another wellestablished commercial mass spectrometer, high resolution-time of flight-aerosol mass spectrometer (HR-ToF-AMS) (Aerodyne research Inc.,) with the aim of quantitative determination of chemical compounds within the atmospheric aerosol particles. In addition, a multi-angle absorption photometer (MAAP, Thermo Sci., model 5012) was also employed to analyze the elemental carbon. An optical particle counter (OPC) and a high-resolution nanoparticle sizer (scanning mobility particle sizer, or SMPS), were measuring the particle size 
distributions of the aerosol particles for the purpose of correcting the number concentrations as measured by the LAAP-ToF-MS. The emerging outcomes of these comprehensive measurements together with the developed methodology to quantify the chemical composition of the atmospheric particles are described below.

\section{Methodology}

Sampling sites and instruments

The measurements were performed from 19 January until 29 January 2015 at the campus of Aix Marseille University situated in the city center of Marseille $\left(43.30^{\circ} \mathrm{N}, 5.38^{\circ} \mathrm{E}\right)$. The site is influenced by many aerosol sources since the sampling point was located about $300 \mathrm{~m}$ from the railway station, $500 \mathrm{~m}$ from the highway and $1.3 \mathrm{~km}$ from the harbor. For these measurements a single particle laser ablation mass spectrometer, LAAP-ToF-MS [6], was applied for on-line and continuous monitoring of single aerosol particles. The working principle of LAAP-ToF-MS is detailed by Gemayel et al. (2016) [6]. Briefly, LAAP-ToF-MS is equipped with aerodynamic lenses which focus particles in the range between $80 \mathrm{~nm}$ and $700 \mathrm{~nm}$ into a narrow beam. The particle beam passes through a nozzle where the particles are accelerated depending on their size (vacuum aerodynamic diameter, $d_{\mathrm{va}}$ ). Then the particle beam travels through two light scattering detection stages (laser diodes, wavelength: $405 \mathrm{~nm}$ ). The vacuum aerodynamic diameter is calculated from the time of flight of the particle between the two detection stages [6]. The second detection stage triggers an excimer laser ( $\prec 193 \mathrm{~nm}$; irradiance: approx. $10^{9}$ $\mathrm{W} \mathrm{cm}^{-2}$ ) (EX 5, GAM Laser, Inc) to pulse and ablate the particles. The Gaussian profile of the laser beam, hot spots in the laser beam and shot-to-shot variation in laser pulse characteristics [7] [8]), are three parameters that strongly affect the ionization and detection of the particles. Therefore, two mathematical quantities are introduced to quantify the detection efficiency, i) the scattering efficiency which corresponds to the ratio between the number of particles detected by the laser diodes and the number of 
particles entering the instrument and ii) the hit rate which is defined as a ratio between the number of particles ionized by the ionization laser and the number of particles detected by the laser diode $([6][25][26])$. The generated ions are analyzed in a bipolar time of flight mass spectrometer with the resolution $\mathrm{m} / \Delta \mathrm{m}>600$.

In this study, LAAP-ToF-MS was used to measure the size-resolved chemical composition of single particles in the size range between $150 \mathrm{~nm}$ and $1 \mu \mathrm{m}$. The dual ion mass spectrum was treated subsequently in MATLAB (R2013b). A HR-ToFAMS[27,28] was used for real-time measurements of size resolved aerosol chemical composition. A Multi-Angle Absorption Photometer (MAAP, Thermo Sci., model 5012) [29] was used to measure elemental carbon, an Optical Particle Counter (OPC 1.109, Grimm) and a high resolution nanoparticle sizer Scanning Mobility Particle Sizer (TSI, SMPS 3936) were used to measure the particle size distributions to correct the number concentrations measured by LAAP-ToF-MS. All instruments were connected to the same sampling system consisting of a TSP (Total suspended particulates) inlet located approximately $3 \mathrm{~m}$ above the ground level. The sampled air was dried using an aerosol diffusion dryer system maintaining the relative humidity in the line below $30 \%$. The sample air flow was then split and diverted to each of the instruments using a custom built flow splitter. In order to allow a direct comparison between the HR-ToF-AMS the LAAP-ToF-MS and the MAAP, a PM1 cyclone was installed at the inlet of the MAAP.

\section{Comparison of the analyzed data}

In a very recent study, Gemayel et al. (2016) reported the low detection efficiency of 2.5 $\%$ for the laser scattering diodes with respect to the particles having a diameter of 450 $\mathrm{nm}$ and even lower detection efficiency for smaller particles. Therefore, it is essential to scale the LAAP-ToF-MS data with those obtained by OPC and SMPS. Then, the next step would be the comparison of the data obtained by LAAP-ToF-MS with the data obtained by HR-ToF-AMS and MAAP. Hence, it is crucial that HR-ToF-AMS and 
1 MAAP are able to detect the total particle mass concentrations. SMPS and OPC detect

2 particles in the range $14 \mathrm{~nm}-650 \mathrm{~nm}$ and $250 \mathrm{~nm}-30 \mu \mathrm{m}$, respectively. Therefore, for comparison purpose and scaling the data of LAAP-ToF-MS the particle concentrations in the range between $150 \mathrm{~nm}$ and $250 \mathrm{~nm}$ measured by SMPS were used in this study. Then for the other size ranges, the particle concentrations measured by the OPC are used. Different types of diameters are measured by the instruments applied in this study, i.e. electrical-mobility diameter for SMPS, geometrical diameter for OPC and aerodynamic diameter for LAAP-ToF-MS. Therefore, the determination of the detection efficiency requires a homogeneity between the three types of diameters.

DeCarlo et al. (2004) reported that geometrical diameter $\left(d_{g}\right)$ is equal to the electricalmobility diameter $\left(d_{m e}\right)$ in case of spherical particles (shape factor $=1$ ). In this study, the particles are considered as spherical which implies an equivalence between geometrical and electrical-mobility diameter [30]. Thereby, to convert these two diameters to vacuum aerodynamic diameter $\left(\mathrm{d}_{\mathrm{va}}\right)$ the Eq-1 is applied

In this case, the factor shape is also considered equal to 1 and the particle density is assumed to be $1.5 \mathrm{~g} \cdot \mathrm{cm}^{-3}$ [1]. However, one should be aware that use of these values for density and shape factor could induce errors to the quantification. The average of shape factor and the average of density is different even for different periods of the day [31,32]. On the other hand, Liu et al. (1999) demonstrated that OPC underestimates the size of ambient particles because they have a refractive index (n) lower than the refractive index of the model particles (in this case polystyrene latex $n=1.6$ ) used to calibrate the OPC [33]. The maximum underestimation of the particle size occurs for particles size comparable to the wavelength ( $2655 \mathrm{~nm})$ used for the OPC. 
2 Scaling of the LAAP-ToF-MS data

3 For data analysis, approximately 112000 dual-ion single-particle mass spectra (Figure

4 1) have been collected for particles in the range between $d_{v a}=225 \mathrm{~nm}\left(d_{m e}=150 \mathrm{~nm}\right)$ and

$5 \quad \mathrm{~d}_{\mathrm{va}}=1.5 \mu \mathrm{m}\left(\mathrm{d}_{\mathrm{me}}=1 \mu \mathrm{m}\right)$.

\section{$6 \quad$ Insert Figure 1}

7 A representative spectrum of the total ionised particles is presented in the Figure 1. In 8 this figure, the standard deviation between the intensities of each $\mathrm{m} / \mathrm{z}$ during the whole duration of the field campaign is presented in function of $\mathrm{m} / \mathrm{z}$ for positive and negative ions. The choice of the standard deviation is based on the aim of this study, to present a maximum of detected ions and to emphasize the ions that change during the measurements. These ions correspond mostly to the typical compounds observed in the urban aerosols: sulfate, nitrate, potassium, ammonium, organic compounds (OC), elemental carbon (EC). Other ions correspond to metals such as iron and lead and ions corresponding to chloride and sodium. The presence of such ions is reasonable considering that the experimental campaign was held near the highway and the harbour. The chloride can be derived from different chemical combinations such as $\mathrm{NaCl}$ (sea salt) or ammonium chloride (industrial aerosol). The discussion about the presence of these ions is further elaborated in section ñDiscussionò. All the collected data are normalized in function of particles size.

Figure 2 shows the repartition of the number of particles in different size ranges as detected by OPC/SMPS and the number of particles ionised by the LAAP-ToF-MS during all the campaign, for particle size ranges corresponding to the one detected by OPC/SMPS. The number of ionised particles by LAAP-ToF-MS is considered as the number of exploitable spectra. The detection efficiency (D \%) of LAAP-ToF-MS is defined as the ratio between the number of 
1 particles sized and ionised by LAAP-ToF-MS and the number of particles measured by

\section{OPC/SMPS.}

\section{Insert figure 2}

4 The detection efficiency of LAAP-ToF-MS varies in function of particle size ranges. For 5 example, it is very low ca. $0.01 \%$ for particle size ranges below $400 \mathrm{~nm}$. Then, starting from $6400 \mathrm{~nm}$ it increases stepwise reaching about $1 \%$ for the size range $580-650 \mathrm{~nm}$, and it remains 7 constant up to $1 \mu \mathrm{m}$. measurements widely varies depending on the number of detected particles. For example, the number of detected particles is very high for the particle range $500-580 \mathrm{~nm}$, and consequently the RSD on the detection efficiency is about $50 \%$. However, the uncertainty of the detection efficiency is more than $200 \%$ for particles size ranges below $400 \mathrm{~nm}$ and over $1000 \mathrm{~nm}$.

To reduce the uncertainty of the quantification, the detection efficiency was averaged every 60 min as described in the section below and the totality of the spectra is grouped into eight different size ranges expressed as $d_{m e}$, as follows: $150-250 \mathrm{~nm}, 250-400 \mathrm{~nm}, 400-450 \mathrm{~nm}, 450-$ $500 \mathrm{~nm}, 500-580 \mathrm{~nm}, 580-650 \mathrm{~nm}, 650-1000 \mathrm{~nm}$. The corresponding RSD are listed as follows $103 ; 106 ; 57 ; 51 ; 50 ; 45$ and $73 \%$, respectively. The first range $(150-250 \mathrm{~nm})$ corresponds to the size range as detected by the SMPS while the others correspond to the size range detected by the OPC.

Methodology

Table 1 lists the ion markers chosen to monitor main particle components by the LAAP-ToFMS. As previously used by single particle mass spectrometer studies (i.e. ATOFMS) $[19,24,34 \ddot{1}$ 37], the list includes sulfate, ammonium, nitrate, chloride, organic compounds (OC) and elemental carbon (EC). 
2 The first step in reducing uncertainties on detection efficiency consists of reducing the shot-to-

3 shot effect due to the inhomogeneity in the laser beam by normalizing the intensities of the

4 specific marker ions produced by the LAAP-ToF-MS (as listed in table 1) to the total ion current

5 (TIC) of the corresponding dual ion spectrum $\left(\mathrm{I}_{\mathrm{i}}\right)$. As a second step, the mean value of the

6 intensity of TIC-normalised marker ions $\left({ }^{1} \mathrm{I}_{\mathrm{i}, \mathrm{t}}\right)$ is calculated for each hour and assigned to

7 different size ranges (different $\mathrm{n})\left({ }^{1} \mathrm{I}_{\mathrm{i}, \mathrm{n}, \mathrm{t}}\right)$.

8 Then the corresponding intensities of different ions $\left({ }^{1} \mathrm{I}_{\mathrm{i}, \mathrm{n}, \mathrm{t}}\right)$ measured by LAAP-ToF-MS are

9 divided by the corresponding size-specific detection efficiency (D) calculated for each hour:

$10 \quad{ }^{1} \mathrm{I}^{\mathrm{D}}{ }_{\mathrm{i}, \mathrm{n}, \mathrm{t}}$.

11 For each particle component and in each particle size range, an average response factor over

12 the whole campaign $($, , ) is determined as

$$
=\frac{-1}{-}
$$

where $^{1-/}$, is the LAAP-ToF-MS averaged scaled ion intensity and ${ }^{-}$, is the mean mass concentration derived from the HR-ToF-AMS data acquired in the P-tof mode [38].

The hourly LAAP-ToF-MS reconstructed mass concentrations were then calculated by dividing the TICï normalised marker ion intensities scaled by the corresponding size-specific detection efficiency, $1 /$, , by the mean size-specific response factor $\mathrm{RF}_{\mathrm{i}, \mathrm{n}}$ and by summing over the whole size range: 
1 The $\mathrm{M}_{\mathrm{i}, \Sigma \mathrm{n}, \mathrm{t}}$ are compared to the hourly averaged mass concentrations measured by HR-ToF-

2 AMS for the same chemical moieties listed in Table $1\left(\mathrm{C}_{\mathrm{i}, \Sigma \mathrm{n}, \mathrm{t}}\right)$. During this campaign, 3 ammonium concentrations were insufficient to work with the P-ToF mode and thus to express

4 these concentrations in function of size range. On the other hand, the MAAP measurements 5 provide a total concentration of EC for particles ranging between $1 \mathrm{~nm}$ and $1000 \mathrm{~nm}$. For the analysis of these two compounds, ammonium and EC an additional step was used to calculate the response factor. The developed methodology is given in the supplementary information.

8 Results

9 Response factor

10 The obtained response factors $\left(\mathrm{RF}_{\mathrm{i}, \mathrm{n}}\right)$ from this study were compared to those obtained by Healy et al. (2013) [18] using an ATOFMS which operational principle (laser ablation) is similar to the one by LAAP-ToF-MS. However, the comparison was not an easy task because the characteristics of the ionisation laser are not the same (ATOFMS: $266 \mathrm{~nm}, \mathrm{E}=1.3 \mathrm{~mJ}$; LAAP-ToF-MS: $193 \mathrm{~nm}, \mathrm{E}=4 \mathrm{~mJ})$. For this reason we compared only the ranking. Another major difference is that the RF in this study were calculated for each size range while the RF in Healy et al. (2013) were estimated for a bulk particle ranging between $150 \mathrm{~nm}$ and $1067 \mathrm{~nm}$. For this reason, the RF of the most abundant size range $(500 \ddot{1} 580 \mathrm{~nm})$ has been chosen for comparison. The relative importance of the RF obtained by the two instruments (LAAP-ToFMS and ATOFMS) were equivalent as shown in Figure $3 \mathrm{~B}$. The RF of the compounds is presented in a decreasing order as follows: EC $>$ sulfate $\sim$ nitrate $>$ organic $>$ ammonium. As a result, in spite of the difference between the two wavelengths used by the two compared instruments (i.e. $193 \mathrm{~nm}$ for LAAP-ToF-MS and $266 \mathrm{~nm}$ for ATOFMS), both instruments give the same result, i.e., the highest signal is obtained for EC and the lowest for OC and ammonium. Although the amount of chloride ions generated per mass unit is in the same order of magnitude as those of nitrate and sulfate, the chloride was not included in this comparison because it was not measured by ATOFMS [18]. 
2 As a second step, the influence of particle size on the absolute RF was examined. As the RF is

3 the ratio between the signal intensity and the mass concentration, a decrease in RF implies that

4 for the same mass concentration the quantity of generated ions decreases. Figure 3 A shows the behavior of the response factor of each chemical compound for different particle sizes. It can be noticed that the RF decreases considerably when the size range increases. As a result, the quantity of generated ions decreases with the particle size but this depends on the considered compound. This result is surprising because the bigger particles should contain higher amount of compounds. Two phenomena could explain this result. First, the light emerging from the excimer laser is independent of the particle size so that, the quantity of energy available per mass unit decreases when the particle size increases [10,39]. The second reason is linked to the particle composition which depends on the size. The composition of the smaller particle facilitates the ionization mechanism $[8,10,39]$. This effect of the matrix will be discussed more in details below.

\section{Evolution of the mass concentration} The results of the comparison between the housrly averaged mass concentrations obtained by the HR-ToF-AMS and MAAP with those derived from the LAAP-ToF-MS are presented in Figure 4 and Figure 5. The time series of the reconstructed mass concentrations from the three instruments are in good agreement.

\section{Insert figure 4}

\section{Insert figure 5}

The difference between the mass concentrations derived from the LAAP-ToF-MS and those given by the HR-ToF-AMS and the MAAP is expressed as an ñerrorò and is calculated according to Eq-4: 
An error equal to zero signifies an excellent agreement between LAAP-ToF-MS and HR-ToFAMS/MAAP. An overestimation by the LAAP-ToF-MS is translated by an error above zero, while an underestimation by the LAAP-ToF-MS is interpreted by an error below zero.

To interpret statistically the good agreement between the two instruments, the concentrations of each compound measured with LAAP-ToF-MS versus HR-ToF-AMS/MAAP are reported on Figure 6. The degree of the agreement increases in the following order $\mathrm{NH}_{4}{ }^{+}<\mathrm{SO}_{4}{ }^{2-}<\mathrm{NO}_{3}{ }^{-}$ $<\mathrm{EC}<\mathrm{OC}<\mathrm{Cl}^{-}$with $\mathrm{r}^{2}$ values in the range of 0.4-0.95 and slopes extrapolated from the linear regressions range between 0.6 and 1.2. This result is satisfying given: i) the uncertainties and assumptions associated to the conversion of ion intensity to mass concentration of chemical species i.e., the factor shape was assumed equal to 1 (spherical particles), the density was considered constant $\left(1.5 \mathrm{~g} \cdot \mathrm{cm}^{-3}\right)$ and the detection efficiency was based on the particle detection instead on the detection of the given compound considered in this study, ii) the limitations generally attributed to single laser mass spectrometers in association with the matrix effect on desorption and ionisation processes.

\section{Insert figure 6}

Three parameters could explain different results obtained during the comparison between LAAP-ToF-MS and HR-ToF-AMS/MAAP: 1) the matrix effect influencing the results using LDI techniques, 2) the detection limit in size (LAAP-ToF-MS: $150 \mathrm{~nm}-1000$ nm; MAAP: PM1) and 3) the effect of relative humidity. In this study, the sampled air was dried using an aerosol diffusion dryer system, which considerably reduces the effect of the relative humidity. Yet, in comparison to the HR-ToF-AMS/MAAP, LAAP-ToF-MS underestimate the mass concentrations of ammonium, EC, sulfate, OC and nitrate (Figure 6). Nevertheless, a statistical test (correlation coefficient) carried out on the errors calculated for the various species, indicates 
that moderate correlations exist between nitrate-sulfate (0.50) and nitrateï OC (0.48), suggesting that these errors are linked mostly to the matrix effect.

\section{Discussion}

The matrix could have an impact on particles detection by mean of the scattering laser and the ionisation rate. Since the effect of the scattering laser is already included in the detection efficiencies values, the attention was focused on the matrix effect on the ionisation rate.

This matrix effect in the laser desorption studies is still misinterpreted and under discussion $[8,40]$. Thomson et al (1997) suggested that the energetic level necessary to obtain an ion production of a constituent strongly depends on other compounds present within the particle under analysis [39]. These authors demonstrated that the ion formation threshold for $\mathrm{NH}_{4} \mathrm{NO}_{3}$ with a $193 \mathrm{~nm}$ ionisation laser, presents the lowest value (4.2-5.6 $\mathrm{MW} \mathrm{cm}{ }^{-2}$ ) compared to the combination of other species such as ammonium sulfate $\left(23-57 \mathrm{MW} \mathrm{cm}^{-2}\right)$. On the other hand, Reinard et al (2008) have shown that numerous interactions exist in the plasma between the ions produced. According to these authors two cases have to be considered:

In plasma with low ion density, few collisions occur between ions, as a result, ions having low electronic affinity will survive and will be dominant. On the other hand, ions with high electronic affinity constitute the lower fraction of the total ion signal [35]. In plasma with high ion density many collisions occur and ions with low electronic affinity are deactivated; the high electronic affinity ions are dominant [35].

In this work, because field experiments were performed and because the analytical results represent hourly averaged values, it is difficult to evaluate the individual relative importance of each phenomenon (the effect of a dense plasma and the effect of the threshold ionisation energy that is, the minimum energy required to produce a detectable ion signal). 
1 Therefore, the interactions between mass concentration of one species and the intensity of other

2 speciesôsignal, were evaluated. For this purpose, the correlations between concentration levels of each species (EC, OC, chloride, ammonium, nitrate and sulfate), and the individual errors of other species were assessed. Errors were calculated based on Eq-4.

These calculations lead to 36 possible combinations for the six considered compounds in this study including the effect of each compound on its own. On a first glance (Figure 7), it can be noticed, for each species, the absence of a systematic correlation between the mass concentration $\left(\mu \mathrm{g} \mathrm{m}^{-3}\right)$ and its own error $(\%)$. This observation immediately discard the possibility of an error associated with the concentrations of the compounds in the sample. Among the 30 remaining combinations, only 8 exhibits statistically relevant correlation coefficients (>0.4) which are shown in Figure 7.

\section{Factors influencing the error on the mass concentrations of $\mathrm{OC}$}

One of the limitations of the single aerosol mass spectrometers based on laser ablation is the variation of the ablation efficiency in function of particle size and chemical composition [41,42]. Kane and Johnston (2000) evaluated the ablation efficiency with respect to simple laboratory-generated oleic acid particles. However, when ablating polydisperse multicomponent aerosols, such as that found in a real atmosphere, the measurements can be influenced greatly by the presence of additional chemical species in the particle. Therefore, they also measured the ablation efficiency of mixed oleic acid and ammonium nitrate in a ratio of about 10:1 by mass. They demonstrated that for each size, ablation efficiencies of the mixed particles are greater than pure oleic acid by a factor of 3 and smaller than pure ammonium nitrate [41].

Even though the average ratio between OC and nitrates is about 3 in this study, it is clear that the presence of ammonium and nitrates has improved the ionization of the OC (figure 7). 
1 Since nitrate and ammonium are simultaneously present in both studies, it is impossible to

2 identify which species (nitrate or ammonium) is responsible for the variation of the signal.

3 In this study a dependence of the OC signal (the same order as the one for nitrates) with respect

4 to the concentration of sulfate was observed. Kane and Johnston (2000) did not evaluated this

5 influence because they followed only positive ions which does not allow sulfate analysis.

\section{$6 \quad$ Insert figure 7}

7 Considering that atmospheric aerosols contain nitrate and sulfate in the form of ammonium

8 nitrate and ammonium sulfate, it can be envisaged that the variation of OC signal is associated

9 with the ammonium rather than nitrate or sulfate. To confirm this hypothesis, additional measurements are necessary with other types of ammonium salts. The ammonium chloride could be a good choice because chloride concentrations does not affect the OC signal.

Factors influencing the error on the mass concentrations of sulfate

The signal of sulfate is largely influnced by the nitrates, the OC, and EC (Figure 7). To the best of authors knowledge, the influence of nitrate and EC on the sulfate, as observed in this study, was not previously evaluated in laboratory experiments. Kane and Johnston (2001) have studied the influence of OC on the signal of sulfate. These authors have shown that coatings of 1naphthyl acetate applied on an aerosol of ammonium sulfate, in a volume ratio 3:1, resulted in a $20 \%$ increase in the detection of sulfate. In the present study, the ratio OC/ sulfate that is 10:1, is expressed in mass concentration; thus cannot be directly compared to the study by Kane and Johnston (2001). The error of the OC signal varies between -100 and $+200 \%$ which results in a total variation of $300 \%$. This dependence with respect to the sulfate exhibits the same trend as the study by Kane and Johnston, (2001) with much bigger values in this study (300\%) against $20 \%$ [42]. The reason for such a big discrepancy is not clear yet. 
Factors influencing the error on the mass concentrations of nitrates

The EC is the only species affecting the error on nitrates signal. This correlation, to the best of authors knowledge was not studied before. On the other hand, in the present study no influence of OC was observed on the nitrates as was also the case in the study by Kane and Johnston (2001) [41].

\section{Factors influencing the error on the mass concentrations of EC}

In a very recent study, Ahern et al. (2106) have demonstrated that the ionization of organics leads to the formation of ion $\mathrm{C}^{+}$which interferes with one of the fragments used to follow the signal of EC [43]. Figure 7 shows that the error on EC is mostly positive ranging between $-80 \%$ and $380 \%$ and that this error is well correlated with the concentration of the organics $\left(\mathrm{R}^{2}=\right.$ 0.42). Thus, it seems that the presence of organics leads to an overestimation of EC.

On the other hand the specific ions which were chosen for the quantification of EC, are exclusively of type $C_{x}{ }^{+}$and $C_{x}{ }^{-}$where $x$ ranges between 1 and 4 . The fragments $C_{x}(x>4)$ were not considered, neither positive nor negative, because the signal/noise was too low. Thus, these $C_{x}(x>4)$ ions could affect the quantitative measurements of EC. Figure 7 shows that OC affects the error of EC which origin could be the modification in the ionization mode of EC, in presence of organic species. Several studies $[36,37,43,44]$ observed such influence of OC on EC, and they even used the fragmentation mode of EC to identify their sources.

In the present study, the response factors of EC are calculated from the $\mathrm{C}_{\mathrm{x}}{ }^{+}$fragments, where $\mathrm{x}$ ranges between 1 and 4 . Nevertheless, the presence of organics favors the fragmentation of EC in a sense that $\mathrm{x}$ in the produced ions of $\mathrm{EC},\left(\mathrm{C}_{\mathrm{x}}{ }^{+/-}\right)$, ranges between 1 and 3 . Under such conditions, all the ions emerged from the ionization of EC were considered, which is not the case for the particles poor in organic material, where EC is less fragmented $\left(\mathrm{C}_{\mathrm{x}}{ }^{+-}\right.$with $\left.1<\mathrm{x}<8\right)$.

MAAP measurements do not cause fragmentation of the atmospheric aerosols in function of particles diameter. Thus, it gives the average mass concentrations for the ensemble of PM1 (all 
the particles with diameter inferior than $1 \mu \mathrm{m})$. On the other hand, LAAP-ToF-MS detects only the particles with diameter $>150 \mathrm{~nm}$. Consequently, the presence of strong concentration of particles with diameter inferior than $150 \mathrm{~nm}$ containing EC would induce an underestimation of EC by LAAP-ToF-MS. This phenomenon was clearly observed during the field campaign on $21^{\text {st }}$ and $26^{\text {th }}$ of January (red square on Figure 5). In this figure it can be seen the concomitance between the high concentrations of particles with diameter $<150 \mathrm{~nm}$ as measured by SMPS and the underestimation of the EC concentrations by LAAP-ToF-MS in comparison to the MAAP measurements.

\section{The correlations emerged from the concurrent measurements}

Figure 6 shows the mass concentrations of each of the considered species (sulfate, ammonium, nitrate, chloride, OC, and EC) measured by LAAP-ToF-MS in function of those obtained by concurrent reference measurements by MAAP for EC, and HR-ToF-AMS for sulfate, OC, nitrate, chloride, and ammonium. The slopes of the regression lines for all the species except chloride are in the range between 0.61 and 0.95 . This implies that a bigger fraction of these species is detected by HR-ToF-AMS.

Contrary, the slope of the regression line 1.2, obtained for chloride signifies that LAAP-ToFMS detects better this species than HR-ToF-AMS. This compound can be present in form of $\mathrm{NaCl}$ in atmospheric aerosols which are considered to emerge from marine sources $[45,46] . \mathrm{In}$ this form the chloride represent refractory species; hence, they cannot be detected by HR-ToFAMS. The field campaign was held in a place situated only $1 \mathrm{~km}$ from the Mediterranean Sea which explains the presence of $\mathrm{NaCl}$ in the detected aerosols by LAAP-ToF-MS. During this campaign, $45 \%$ of the particles containing chloride were containing sodium as well. The relative standard deviation obtained on the average value of chloride was $43 \%$ which explain a high variability in the percentage of chloride in the form of $\mathrm{NaCl}$. Therefore, this variability in 
1 the percentage of chloride detected by the LAAP-ToF-MS is responsible of the overestimation

2 of these ions since the HR-ToF-AMS showed less variability.

\section{Conclusion}

4 LAAP-ToF-MS as a single aerosol mass spectrometer based on laser desorption ionization

5 technique is capable of measuring the time evolution of mass concentrations. This study

6 revealed the importance of four points (described below) which need to be optimized in order to quantify the chemical composition of aerosol particles by LAAP-ToF-MS.

1: An absolute quantification of chemical species during a field campaign is a complex issue due to matrix effects, especially if the measurement site is affected by different sources of aerosols, as was the case in this study. However, a semi-quantification allowing to monitor the evolution of a chemical composition in function of time is possible. Therefore, detected particles should be classified in different classes depending on their composition, i.e. particles containing sulfate and nitrate are considered as one class while those containing only sulfate represents another class. By this, the matrix effect would be surmounted. Then the next point should be applied.

2: The determination of the mass concentration of a chemical composition should respect three important points. First of all, it is important to consider the sum of all the specific ions of each chemical composition. Second, the corresponding intensities of these ions have to be normalized to the detection efficiency. And at last but not least, one have to choose a suitable time interval leading to an overall chemical composition statistically sufficient to overcome the shot-to-shot effect of lasers variability. In this study a time interval including 15 particles was found to be suitable for quantification of mass concentrations. 
1 3: An absolute qquantification would be possible in the case of measurements at the source. In

2 this case the chemical composition within the aerosol is stable (not influenced by various

3 sources) and the effect of matrix would not significantly affect the quantification.

4 4: In the present study, the HR-ToF-AMS used as a reference instrument does not detect 5 chloride present as $\mathrm{NaCl}$, explaining the overestimation of chloride obtained from the LAAP-

6 ToF-MS measurements. Therefore, the quantification of chloride using the LAAP-ToF-MS

7 needs to be compared to an instrument capable of measuring all the possible states of chloride

8 possibly present in an aerosol. In the future, development of a methodology based on laboratory

9 studies and calculation of the response factors by type of particles, would resolve certain 10 difficulties associated with the matrix effect.

11 Acknowledgements.

12 This work is a contribution to the LABEX SERENADE (no. ANR-11-LABX-0064) funded 13 by the ñnvestisse- ments dôAvenirò, French Government program of the French National 14 Research Agency (ANR) through the A*Midex project (No. ANR-11-IDEX-0001-02).

15 The authors gratefully acknowledge the support of this work by French National Agency of 16 Research within the ANR-10-EQPX-39-01. 
1 References

2 [1] R.M. Healy, J. Sciare, L. Poulain, K. Kamili, M. Merkel, T. Muller, a. Wiedensohler,

3

S. Eckhardt, a. Stohl, R. Sarda-Est??ve, E. McGillicuddy, I.P. OâConnor, J.R. Sodeau, J.C. Wenger, Sources and mixing state of size-resolved elemental carbon particles in a European megacity: Paris, Atmospheric Chemistry and Physics. 12 (2012) 1681171700. doi:10.5194/acp-12-1681-2012.

[2] C.. Pope, Invited Commentary: Particulate Matter-Mortality Exposure-Response Relations and Threshold, American Journal of Epidemilogy. 152 (2000) $407 i ̈ 412$.

[3] J. Lelieveld, J. Evans, M. Fnais, D. Giannadaki, A. Pozzer, The contribution of outdoor air pollution sources to premature mortality on a global scale, Nature. 525 (2015) 367ï 371.

[4] IPCC, Intergovernmental Panel on Climate Change, Climate Change fifth report, 2013.

[5] S. Gligorovski, J.. Van Elteren, I. Grgic, A multi-element mapping approach for sizesegregated atmospheric particles using laser ablation ICP-MS combined with image analysis, Science of the Total Environment. 407 (2008) 594ї 602.

[6] R. Gemayel, S. Hellebust, B. Temime-Roussel, N. Hayeck, J.T. Van Elteren, H. Wortham, S. Gligorovski, The performance and the characterization of laser ablation aerosol particle time-of-flight mass spectrometry (LAAP-ToF-MS), Atmospheric Measurement Techniques. 9 (2016) 1947ï 1959. doi:10.5194/amt-9-1947-2016.

[7] R.J. Wenzel, K.A. Prather, Improvements in ion signal reproducibility obtained using a homogeneous laser beam for on-line laser desorption/ionization of single particles, Rapid Communications in Mass Spectrometry. 18 (2004) 1525ï 1533. doi:10.1002/rcm.1509. 
1 [8] D.S. Gross, M.E. Galli, P.J. Silva, K. a Prather, Relative sensitivity factors for alkali metal and ammonium cations in single particle aerosol time-of-flight mass spectra, Analytical Chemistry. 72 (2000) 416ï 422. <Go to ISI>://000084855300022.

[9] D.-Y. Liu, Aerosol time-of-flight mass spectrometry during the Atlanta Supersite Experiment: 1. Measurements, Journal of Geophysical Research. 108 (2003) 8426. doi:10.1029/2001JD001562.

[10] D.P. Fergenson, X.H. Song, Z. Ramadan, J.O. Allen, L.S. Hughes, G.R. Cass, P.K. Hopke, K.A. Prather, Quantification of ATOFMS data by multivariate methods, Analytical Chemistry. 73 (2001) 3535ї 3541. doi:10.1021/ac010022j.

[11] D.A. Lake, M.P. Tolocka, M. V. Johnston, A.S. Wexler, Mass spectrometry of individual particles between 50 and $750 \mathrm{~nm}$ in diameter at the Baltimore supersite, Environmental Science and Technology. 37 (2003) $3268 і ̈ 3274$. doi:10.1021/es026270u.

[12] R.C. Moffet, L.G. Shields, J. Berntsen, R.B. Devlin, K.A. Prather, Characterization of an ambient coarse particle concentrator used for human exposure studies: Aerosol size distributions, chemical composition, and concentration enrichment, Aerosol Science and Technology. 38 (2004) 1123ї 1137. doi:10.1080/027868290890344.

[13] D.A. Sodeman, S.M. Toner, K.A. Prather, Determination of single particle mass spectral signatures from light-duty vehicle emissions, Environmental Science \& Technology. 39 (2005) 4569ï 4580. doi:10.1021/es0489947.

[14] Y. Zhou, X.H.H. Huang, S.M. Griffith, M. Li, L. Li, Z. Zhou, C. Wu, J. Meng, C.K. Chan, P.K.K. Louie, J.Z. Yu, A field measurement based scaling approach for quantification of major ions, organic carbon, and elemental carbon using a single 
particle aerosol mass spectrometer, Atmospheric Environment. 143 (2016) 300ї 312. doi:10.1016/j.atmosenv.2016.08.054.

[15] P. V. Bhave, J.O. Allen, B.D. Morrical, D.P. Fergenson, G.R. Cass, K.A. Prather, A field-based approach for determining ATOFMS instrument sensitivities to ammonium and nitrate, Environmental Science and Technology. 36 (2002) $4868 і ̈ 4879$. doi:10.1021/es015823i.

[16] E. Woods, G.D. Smith, Y. Dessiaterik, T. Baer, R.E. Miller, Quantitative detection of aromatic compounds in single aerosol particle mass spectrometry, Analytical Chemistry. 73 (2001) 2317ï 2322. doi:10.1021/ac0011661.

[17] D. Lee, K. Park, M.R. Zachariah, Determination of the Size Distribution of Polydisperse Nanoparticles with Single-Particle Mass Spectrometry: The Role of Ion Kinetic Energy, Aerosol Science and Technology. 39 (2005) 1621169.

[18] R.M. Healy, J. Sciare, L. Poulain, M. Crippa, A. Wiedensohler, A.S.H. Pr??v??t, U. Baltensperger, R. Sarda-Est??ve, M.L. McGuire, C.H. Jeong, E. McGillicuddy, I.P. OâConnor, J.R. Sodeau, G.J. Evans, J.C. Wenger, Quantitative determination of carbonaceous particle mixing state in Paris using single-particle mass spectrometer and aerosol mass spectrometer measurements, Atmospheric Chemistry and Physics. 13 (2013) 9479ї 9496. doi:10.5194/acp-13-9479-2013.

[19] C.H. Jeong, M.L. McGuire, K.J. Godri, J.G. Slowik, P.J.G. Rehbein, G.J. Evans, Quantification of aerosol chemical composition using continuous single particle measurements, Atmospheric Chemistry and Physics. 11 (2011) $7027 i ̈ 7044$. doi:10.5194/acp-11-7027-2011.

[20] D.C.. Beddows, R.. Donovan, R.. Harrision, M.. Heal, R. Kinnersley, M.. King, D.. 
Nicholson, M.-J. Schofield, K.. Thompson, Variations in the Chemical Composition of the Rural Background Atmospheric Aerosol Determined Real Time Using Time-ofFlight Mass Spectroscopy, Journal of Environmental Monitoring. 2 (2004) $124 і ̈ 133$.

[21] S.R. Guazzotti, K.R. Coffee, K.A. Prather, Continuous measurements of size resolved particle chemistry during INDOEX-IFP 99, Journal of Geophysical Research. 106 (2001) $607 і ̈ 627$.

[22] D.Y. Liu, R.J. Wenzel, K.A. Prather, Aerosol Time-of-Flight Mass Spectrometry during the Atlanta Supersite Experiment: 1. Measurements, Journal of Geophysical Research Atmospheres. 108 (2003).

[23] S.H. Pastor, J.O. Allen, L.S. Hughes, P. Bhave, G.R. Cass, K.A. Prather, Ambient Single Particle Analysis in Riverside, California by Aerosol Time-of-Flight Mass Spectrometry during the SCOS97-NARSTO, Atmospheric Environment. 37 (2003) $239 \ddot{2} 258$.

[24] X. Qin, P. V. Bhave, K.A. Prather, Comparison of two methods for obtaining quantitative mass concentrations from aerosol time-of-flight mass spectrometry measurements, Analytical Chemistry. 78 (2006) 6169ï 6178. doi:10.1021/ac060395q.

[25] Y. Su, M.F. Sipin, H. Furutani, K.A. Prather, Development and Characterization of an Aerosol Time-of-Flight Mass Spectrometer with Increased Detection Efficiency, Analytical Chemistry. 76 (2004) 712ï 719. doi:10.1021/ac034797z.

[26] F. Gaie-Levrel, S. Perrier, E. Perraudin, C. Stoll, N. Grand, M. Schwell, Development and characterization of a single particle laser ablation mass spectrometer (SPLAM) for organic aerosol studies, Atmospheric Measurement Techniques. 5 (2012) $225 і ̈ 241$. doi:10.5194/amt-5-225-2012. 
1 [27] J.T. Jayne, D.C. Leard, X.F. Zhang, P. Davidovits, K. a Smith, C.E. Kolb, D.R. Worsnop, Development of an aerosol mass spectrometer for size and composition analysis of submicron particles, Aerosol Science and Technology. 33 (2000) $49 \ddot{1} 70$. doi:10.1080/027868200410840.

[28] P.F. Decarlo, J.R. Kimmel, A. Trimborn, M.J. Northway, J.T. Jayne, A.C. Aiken, M. Gonin, K. Fuhrer, T. Horvath, K.S. Docherty, D.R. Worsnop, J.L. Jimenez, Aerosol Mass Spectrometer, Analytical Chemistry. 78 (2006) $8281 і ̈ 8289$. doi:8410.1029/2001JD001213.Analytical.

[29] A. Petzold, M. Schönlinner, Multi-angle absorption photometry - A new method for the measurement of aerosol light absorption and atmospheric black carbon, Journal of Aerosol Science. 35 (2004) 421ї 441. doi:10.1016/j.jaerosci.2003.09.005.

[30] P. DeCarlo, J. Slowik, K. Stainken, P. Davidovits, L.R. Williams, J.T. Jayne, C.E. Kolb, D. Worsnop, Y. Rudich, J. Jimenez, Particle Morphology and Density Characterization by Combined Mobility and Aerodynamic Diameter Measurements. Part 2: Application to Combustion-Generated Soot Aerosols as a Function of Fuel Equivalence Ratio, Aerosol Science and Technology. 38 (2004) 120612122. doi:10.1080/02786826.2004.10399462.

[31] M. Pitz, J. Cyrys, E. Karg, A. Wiedensohler, H.E. Wichmann, J. Heinrich, Variability of apparent particle density of an urban aerosol, Environmental Science and Technology. 37 (2003) 4336ï 4342. doi:10.1021/es034322p.

[32] R. McDonald, P. Biswas, NIH Public Access, 54 (2008) 1069ï 1078.

[33] Y. Liu, P.H. Daum, *Corresponding Author, (1999) 1 ï 36.

[34] A. Bharti, P.C. Ma, R. Salgia, Biomarker discovery in lung cancer--promises and 
challenges of clinical proteomics., Mass Spectrometry Reviews. 26 (2007) $451 і ̈ 466$. doi:10.1002/mas.

[35] M.S. Reinard, M. V. Johnston, Ion Formation Mechanism in Laser Desorption Ionization of Individual Nanoparticles, Journal of the American Society for Mass Spectrometry. 19 (2008) 389ї 399. doi:10.1016/j.jasms.2007.11.017.

[36] M.T. Spencer, K. a. Prather, Using ATOFMS to Determine OC/EC Mass Fractions in Particles, Aerosol Science and Technology. 40 (2006) 585 ï 594. doi:10.1080/02786820600729138.

[37] J.F. Cahill, K. Suski, J.H. Seinfeld, R.A. Zaveri, K.A. Prather, The mixing state of carbonaceous aerosol particles in northern and southern California measured during CARES and CalNex 2010, Atmospheric Chemistry and Physics. 12 (2012) 10989ї 11002. doi:10.5194/acp-12-10989-2012.

[38] P. DeCarlo, J. Kimmel, A. Trimborn, M. Northway, J. Jayne, A. Aiken, M. Gonin, K. Fuhrer, T. Horvath, K. Docherty, D. Worsnop, J. Jimenez, Field-deployable, highresolution, time-of-flight aerosol mass spectrometer., Analytical Chemistry. 78 (2006) 8281118289.

[39] D.S. Thomson, a M. Middlebrook, D.M. Murphy, Thresholds for laser-induced ion formation from aerosols in a vacuum using ultraviolet and vacuum-ultraviolet laser wavelengths, Aerosol Science and Technology. 26 (1997) $544 і ̈ 559$. doi:10.1080/02786829708965452.

[40] A.L. Van Wuijckhuijse, M.A. Stowers, W.A. Kleefsman, B.L.M. Van Baar, C.E. Kientz, J.C.M. Marijnissen, Matrix-assisted laser desorption/ionisation aerosol time-offlight mass spectrometry for the analysis of bioaerosols: Development of a fast detector 
[41] D.B. Kane, M. V. Johnston, Size and Composition Biases on the Detection of Individual Ultrafine Particles by Aerosol Mass Spectrometry, Environmental Science \& Technology. 34 (2000) 4887ï 4893. doi:10.1021/es001323y.

[42] D.B. Kane, M. V Johnston, Enhancing the detection of sulfate particles for laser ablation aerosol mass spectrometry., Analytical Chemistry. 73 (2001) 53651 9. doi:10.1021/ac010469s.

[43] A.T. Ahern, R. Subramanian, G. Saliba, E.M. Lipsky, N.M. Donahue, R.C. Sullivan, Effect of secondary organic aerosol coating thickness on the real-time detection and characterization of biomass burning soot by two particle mass spectrometers, Atmospheric Measurement Techniques Discussions. 2 (2016) 1ї 27. doi:10.5194/amt2016-201.

[44] J.C. Corbin, B. Sierau, M. Gysel, M. Laborde, A. Keller, J. Kim, A. Petzold, T.B. Onasch, U. Lohmann, A.A. Mensah, Mass spectrometry of refractory black carbon particles from six sources: Carbon-cluster and oxygenated ions, Atmospheric Chemistry and Physics. 14 (2014) 2591ї 2603. doi:10.5194/acp-14-2591-2014.

[45] M. Millet, A. Sanusi, H. Wotham, Chemical composition of fogwater in an urban area: Strasbourg (France), Environmental Pollution. 3 (1996) $345 і ̈ 354$.

[46] A. Sanusi, H. Wortham, M. Millet, P. Mirabel, Chemical composition of rain water and pollution origin in Eastern France., Atmospheric Environment. 30 (1996) 59 ï̈ 72. 